\title{
State transformations and ice nucleation in amorphous (semi-)solid organic aerosol
}

\author{
K. J. Baustian ${ }^{1,2, *}$, M. E. Wise ${ }^{1, * *}$, E. J. Jensen ${ }^{3}$, G. P. Schill ${ }^{1,4}$, M. A. Freedman ${ }^{5}$, and M. A. Tolbert ${ }^{1,4}$ \\ ${ }^{1}$ Cooperative Institute for Research in Environmental Sciences, University of Colorado, Boulder, CO, 80309, USA \\ ${ }^{2}$ Department of Atmospheric and Oceanic Science, University of Colorado, Boulder, CO, 80309, USA \\ ${ }^{3}$ NASA Ames Research Center, Moffett Field, CA, USA \\ ${ }^{4}$ Department of Chemistry and Biochemistry, University of Colorado, Boulder, CO, 80309, USA \\ ${ }^{5}$ Department of Chemistry, The Pennsylvania State University, 104 Chemistry Building, University Park, Pennsylvania \\ 16802, USA \\ *now at: School of Earth and Environment, University of Leeds, Leeds, UK \\ ** now at: College of Theology, Arts and Sciences, Concordia University, Portland, OR, 97211, USA
}

Correspondence to: K. J. Baustian (k.baustian@leeds.ac.uk)

Received: 10 October 2012 - Published in Atmos. Chem. Phys. Discuss.: 17 October 2012

Revised: 6 May 2013 - Accepted: 7 May 2013 - Published: 7 June 2013

\begin{abstract}
Amorphous (semi-)solid organic aerosol particles have the potential to serve as surfaces for heterogeneous ice nucleation in cirrus clouds. Raman spectroscopy and optical microscopy have been used in conjunction with a cold stage to examine water uptake and ice nucleation on individual amorphous (semi-)solid particles at atmospherically relevant temperatures (200-273 K). Three organic compounds considered proxies for atmospheric secondary organic aerosol (SOA) were used in this investigation: sucrose, citric acid and glucose. Internally mixed particles consisting of each organic and ammonium sulfate were also investigated.

Results from water uptake experiments followed the shape of a humidity-induced glass transition $\left(T_{\mathrm{g}}(\mathrm{RH})\right)$ curve and were used to construct state diagrams for each organic and corresponding mixture. Experimentally derived $T_{\mathrm{g}}(\mathrm{RH})$ curves are in good agreement with theoretical predictions of $T_{\mathrm{g}}(\mathrm{RH})$ following the approach of Koop et al. (2011). A unique humidity-induced glass transition point on each state diagram, $T_{\mathrm{g}}^{\prime}(\mathrm{RH})$, was used to quantify and compare results from this study to previous works. Values of $T_{\mathrm{g}}^{\prime}(\mathrm{RH})$ determined for sucrose, glucose and citric acid glasses were 236,230 and $220 \mathrm{~K}$, respectively. Values of $T_{\mathrm{g}}^{\prime}(\mathrm{RH})$ for internally mixed organic/sulfate particles were always significantly lower; 210, 207 and $215 \mathrm{~K}$ for sucrose/sulfate, glucose/sulfate and citric acid/sulfate, respectively.
\end{abstract}

All investigated SOA proxies were observed to act as heterogeneous ice nuclei at tropospheric temperatures. Heterogeneous ice nucleation on pure organic particles occurred at $S_{\text {ice }}=1.1-1.4$ for temperatures below $235 \mathrm{~K}$. Particles consisting of 1:1 organic-sulfate mixtures took up water over a greater range of conditions but were in some cases also observed to heterogeneously nucleate ice at temperatures below $202 \mathrm{~K}\left(S_{\text {ice }}=1.25-1.38\right)$.

Polynomial curves were fitted to experimental water uptake data and then incorporated into the Community Aerosol Radiation Model for Atmospheres (CARMA) along with the predicted range of humidity-induced glass transition temperatures for atmospheric SOA from Koop et al. (2011). Model results suggest that organic and organic/sulfate aerosol could be glassy more than $60 \%$ of the time in the midlatitude upper troposphere and more than $40 \%$ of the time in the tropical tropopause region (TTL). At conditions favorable for ice formation $\left(S_{\text {ice }}>1\right)$, particles in the TTL are expected to be glassy more than $50 \%$ of the time for temperatures below $200 \mathrm{~K}$. Results from this study suggests that amorphous (semi-)solid organic particles are often present in the upper troposphere and that heterogeneous ice formation on this type of particle may play an important role in cirrus cloud formation. 


\section{Introduction}

Organic compounds are ubiquitous in tropospheric aerosol and often account for a large portion of aerosol mass (e.g., Froyd et al., 2010; and Zhang et al., 2007). A growing body of literature has shown that certain types of organic aerosol may exist as amorphous glasses or semi-solids at atmospherically relevant temperatures and relative humidities (RH) (Bones et al., 2012; Murray, 2008; Mikhailov et al., 2009; Saukko, 2012; Shiraiwa et al., 2011, 2012; Tong et al., 2011; Virtanen et al., 2010; Zobrist et al., 2008). Viscosity is the physical property most often used to distinguish these phases. The term glassy solid is used to describe an amorphous material that lacks the long-range molecular order of a crystal but behaves mechanically like a solid due to extremely high viscosity ( $>10^{12} \mathrm{~Pa} \mathrm{~s}$, Angell, 1995; Debenedetti and Stillinger, 2001). In contrast, the viscosity of a liquid is on the order of $10^{-3} \mathrm{Pas}$ and between $10^{2}$ and $10^{12} \mathrm{~Pa}$ s for semi-solid substances (Shiraiwa et al., 2011). The transition between a semi-solid and glass is often defined according to a characteristic glass transition temperature $\left(T_{\mathrm{g}}\right)$, below which the viscosity of the substance is $>10^{12} \mathrm{Pas}$.

The formation of amorphous (semi-)solids and their interaction with water vapor have been reviewed by Debenedetti and Stillinger (2001) and examined in the context of atmospheric aerosol by Koop et al. (2011) and Mikhailov et al. (2009). Predicting the $T_{\mathrm{g}}$ of atmospheric aerosol is nontrivial because it is dependent on many factors including aerosol composition, temperature, $\mathrm{RH}$, rate of change of temperature and $\mathrm{RH}$, and aerosol mixing state of the particles. Zobrist et al. (2008) have shown that while many inorganic salt solutions have $T_{\mathrm{g}}$ values too low to be of importance in the atmosphere, mixtures of inorganics and oxygenated organics often have $T_{\mathrm{g}}$ values that fall within an atmospherically relevant temperature range. They suggest that glassy organic aerosol could influence water uptake and ice nucleation processes in the upper troposphere. A number of studies have provided evidence that supports this hypothesis. Koop et al. (2011) have demonstrated that typical precursors for biogenic SOA (i.e., $\alpha$-pinene and isoprene), when oxidized, have $T_{\mathrm{g}}$ values within the range of atmospheric relevance. Murray et al. (2012) demonstrated the solid-like behavior of iodic acid solution droplets at low RH by applying mechanical pressure. Particles shattered in a manner consistent with an ultra-viscous or glassy solid. Virtanen et al. (2010) and Saukko et al. (2012) have also inferred the solid-like behavior of SOA particles and proxies at ambient temperatures and low RH using inertial impaction and particle bounce as an indirect measurement of viscosity. Saukko et al. (2012) found that bounce factor increased with further oxidation of SOA particles, whereas increased concentrations of sulfuric acid decreased particle bounce factor by lowering viscosity. Evidence that a glassy or amorphous aerosol phase influences water uptake, evaporation, diffusion, sorption and chemical aging in atmospheric aerosol particles has also been put forth in several other recent studies (Bones et al., 2012; Cappa and Wilson, 2011; Roth et al., 2005; Shiraiwa et al., 2011, 2012; Vaden et al., 2011; Wang et al., 2012a).

The present work investigates state transitions in organic aerosol and the impact of phase state on heterogeneous ice formation in cirrus clouds. Ice crystals form on or in ambient aerosol particles, termed ice nuclei (IN), which serve as surfaces for ice nucleation and growth in the atmosphere. Ice formation from liquid aerosol particles proceeds via a homogeneous ice nucleation pathway (Koop et al., 2000) whereas heterogeneous ice nucleation is catalyzed by a solid surface, such as an insoluble aerosol particle (Pruppacher and Klett, 1997). Particle phase will therefore determine the pathway(s) by which ice nucleation can proceed. If glassy aerosol particles are present at conditions conducive to ice formation, they could potentially serve as heterogeneous IN via the immersion, contact and depositional freezing modes. Depositional ice nucleation arises from the supersaturated vapor phase. Immersion freezing occurs from a supercooled aqueous droplet whereas contact freezing occurs from the collision of an IN with a supercooled aqueous droplet. Cirrus clouds formed via a homogeneous mechanism will have very different properties than those formed through a heterogeneous nucleation process. Due to a low level of scientific understanding, ice cloud formation is currently not well characterized in global models and represents a large uncertainty in predictions of climate change (Forster et al., 2007). It is therefore important that we determine whether glassy organic aerosol exists at conditions favorable for ice cloud formation, and if so, investigate ice nucleation on such particles.

There are only a few previous studies of ice nucleation on particles known to be glassy (Murray et al., 2010; Wagner et al., 2012; Wang et al., 2012a; Wilson et al., 2012). In cloud chamber experiments Murray et al. (2010) demonstrated that heterogeneous ice nucleation on glassy citric acid particles occurs at lower ice saturation ratios $\left(S_{\text {ice }}(T)=\right.$ $P_{\mathrm{H}_{2} \mathrm{O}} / \mathrm{VP}_{\text {ice }}(T)$, where $P_{\mathrm{H}_{2} \mathrm{O}}$ is water vapor partial pressure and $\mathrm{VP}_{\text {ice }}$ is equilibrium vapor pressure of water over ice) than in aqueous citric acid aerosol ( $S_{\text {ice }} \sim 1.2$ on glassy vs. $S_{\text {ice }} \sim 1.6$ for liquid). In a follow-up study using glassy organic aerosol with a range of $T_{\mathrm{g}}$ values, Wilson et al. (2012) observed heterogeneous ice nucleation at $S_{\text {ice }}$ values ranging from 1.2 and 1.6 for temperatures near $200 \mathrm{~K}$. For the same set of experiments, Wagner et al. (2012) describes a mechanism by which initial homogeneous freezing may create a subset of amorphous aerosol particles that could then serve as highly efficient heterogeneous IN. Wang et al. (2012a) investigated water uptake and ice nucleation on laboratorygenerated glassy naphthalene SOA. Both immersion and deposition mode freezing were observed on these samples below the homogeneous ice nucleation threshold.

In the present study, we have used Raman spectroscopy and optical microscopy to investigate how state transitions 
influence ice nucleation in organic aerosol particles over a range of atmospherically relevant conditions. The Raman system was used to probe water uptake and ice nucleation at the level of the individual micron-sized particle. State diagrams constructed from experimental results were used to predict organic aerosol phase over a large range of temperatures and RH. Ice nucleation experiments were performed to determine conditions under which glass-forming organic aerosol may serve as heterogeneous IN. Laboratory results were also incorporated into the Community Aerosol Radiation Model for Atmospheres (CARMA) to estimate the fraction of time organic particles are likely to be glassy versus liquid in the midlatitude upper troposphere and TTL regions.

\section{Experimental}

Sucrose, glucose and citric acid are all soluble organic species known to form glasses at atmospherically relevant conditions. These organics were chosen because they have similar functionality to soluble organic material commonly found in tropospheric aerosol particles (Graham et al., 2003) and have been used in previous investigations of glassy aerosol (Bones et al., 2012; Murray et al., 2010; Zobrist et al., 2008, 2011; Lienhard et al., 2012; Koop et al., 2011).

Tropospheric aerosol often consists of organic material internally mixed with significant fractions of inorganic compounds (e.g., Cziczo et al., 2004; and Murphy et al., 2006). Single-particle mass spectrometry has further shown that background aerosol near the TTL $(\sim 12-18 \mathrm{~km}, \sim 180$ $200 \mathrm{~K}$ ) consists mainly of internally mixed oxygenated organics and sulfates with an average organic mass fraction of $50 \%$ (Froyd et al., 2010). For this reason, internally mixed particles containing equal parts organic and ammonium sulfate were also investigated in this study.

\subsection{Particle generation}

Aerosol samples were created by drying aqueous organic aerosol generated via atomization. Particles were produced by delivering a $10 \mathrm{wt} \%$ solution of each organic (or 10 wt \% 1:1 mixture with ammonium sulfate) to an atomizer (TSI 3076) at a rate of $2 \mathrm{~mL} \mathrm{~min}^{-1}$ using a Harvard apparatus syringe pump. Particles were impacted directly onto a silanized quartz substrate ( $1 \mathrm{~mm}$ thick) in a flow of dry $\mathrm{N}_{2}$ at $0.6 \mathrm{~L} \mathrm{~min}^{-1}$. The resulting particles had diameters between 1 and $10 \mu \mathrm{m}$ with an average size of $\sim 4 \mu \mathrm{m}$. All particles used for investigation of water uptake in this study were between 3 and $8 \mu \mathrm{m}$ initial diameter.

Samples were placed in an experimental flow cell and exposed to an environment of dry $\mathrm{N}_{2}(\mathrm{RH}=0 \%, T=$ $298 \mathrm{~K})$. Particles were conditioned at $0 \% \mathrm{RH}$ and considered glassy, or at least to contain a glassy outer shell, if the following criteria were met: Raman spectra showed that particles were noncrystalline, particles were spherical and demonstrated water uptake that was not consistent with crystalline deliquescence. Water uptake by an amorphous (semi-)solid substance in a humid environment is referred to as a moisture-induced phase transition or amorphous deliquescence (Mikhailov et al., 2009). Raman spectra of citric acid shown in Fig. 1 provide an example of differences between crystalline and amorphous deliquescence. Raman spectra of crystalline citric acid, for example the bottom spectrum in the left panel of Fig. 1, have sharp peaks in the $\mathrm{O}-\mathrm{H}$ and $\mathrm{C}-\mathrm{H}$ stretching region between $3100-3600 \mathrm{~cm}^{-1}$ and $2900-3100 \mathrm{~cm}^{-1}$. In contrast, Raman spectra amorphous citric acid particles (bottom spectrum in the right panel of Fig. 1) have single broad peaks in these same regions. Peak broadening in the spectra occurs due to the disordered nature of $\mathrm{O}-\mathrm{H}$ and $\mathrm{C}-\mathrm{H}$ bonds in the amorphous species versus a well-ordered crystalline solid. Samples were held at room temperature and $0 \% \mathrm{RH}$ until spectral subtraction showed that the water content of particles remained constant. Raw spectral data was used for subtractions without background correction however spectra were normalized using the intensity of the $\mathrm{C}-\mathrm{H}$ peaks prior to subtraction. Spectral subtractions from the water uptake experiment presented in Fig. 1 are shown in Appendix A, Fig. A1 for reference. Glassy particles were never observed to effloresce, even when left for more than $24 \mathrm{~h}$ at $0 \% \mathrm{RH}$.

Crystalline samples could not be generated from atomized liquid particles due to inhibition of crystallization in concentrated organic solutions (Bodsworth et al., 2010). For experiments starting from crystalline species, a mortar and pestle was used to grind the pure crystalline material at room temperature and humidity. A small amount of the finely ground material was placed on a quartz substrate and gently tapped to free large crystals.

\subsection{Water uptake and ice nucleation experiments}

Water uptake and ice nucleation experiments presented in this study were performed using a Raman spectrometer paired with an optical microscope, temperature-controlled environmental cell and chilled-mirror hygrometer. This experimental setup and methods have been previously described in detail (Baustian et al., 2010; Wise et al., 2012; Schill and Tolbert, 2012b) and are therefore described only briefly here.

Directly following preparation, samples were placed into the experimental flow cell and conditioned in a dry environment at $298 \mathrm{~K}$. An experiment began by introducing water vapor into the $\mathrm{N}_{2}$ stream. $\mathrm{RH}$ inside the cell was continuously monitored using a Buck Research CR-1A chilled-mirror hygrometer. Samples were held at $298 \mathrm{~K}$ until the humidity level desired for each experiment was reached and allowed to stabilize. RH was further increased by cooling samples at a rate of $30 \mathrm{~K} \mathrm{~min}^{-1}$, until the RH environment over a sample was $\sim 90 \%$ of that required for deliquescence. After the initial cooling phase, samples were held at one temperature and 
humidity level for $>5$ min to ensure temperature stabilization. A slow temperature ramp, cooling rate of $0.1 \mathrm{~K} \mathrm{~min}^{-1}$, was then initiated. This rate was chosen because it is similar to the cooling rate an air parcel might experience in mid and low latitude cirrus clouds (Karcher and Strom, 2003). Samples were cooled continuously and monitored at least every $0.2 \mathrm{~K}$, using both visual inspection and Raman spectroscopy, until water uptake and/or ice formation was observed. For example, if the onset of water uptake was expected to occur between 50 and $60 \% \mathrm{RH}$, a sample was cooled at $30 \mathrm{~K} \mathrm{~min}^{-1}$ until RH above the particles was $\sim 45 \%$. After temperature equilibrium was established the sample was cooled at a rate of $0.1 \mathrm{~K} \mathrm{~min}^{-1}$ until the onset of water uptake was observed. Spectral subtraction was used to specifically determine $\mathrm{RH}$ at the onset of water uptake (e.g., Fig. A1).

$S_{\text {ice }}$ was also monitored and used to quantify the onset of ice nucleation events. Values were derived experimentally from the ratio of $P_{\mathrm{H}_{2} \mathrm{O}}$ to $\mathrm{VP}_{\text {ice }}(T) . P_{\mathrm{H}_{2} \mathrm{O}}$ was determined from frost point values measured by a chilled-mirror hygrometer (Buck, 1981). $\mathrm{VP}_{\text {ice }}(T)$ was calculated using calibrated sample temperature and vapor pressure formulations from Murphy and Koop (2005). Uncertainties in $S_{\text {ice }}$ values listed throughout the manuscript $( \pm 0.05)$ reflect one standard deviation of uncertainty in the temperature calibration of the environmental cell. During experiments in which water vapor saturation with respect to ice was reached and/or surpassed, the sample was monitored for both water uptake (using Raman spectroscopy) and the onset of ice nucleation (using 10X optical magnification). For every experiment performed in this study the slow cooling phase $\left(0.1 \mathrm{~K} \mathrm{~min}^{-1}\right)$ was initiated below saturation with respect to ice $\left(S_{\text {ice }}<0.9\right)$. After ice nucleation was detected, the final step in every experiment was sublimation of the ice, revealing the particle responsible for nucleation. The IN was then inspected using both optical microscopy and Raman spectroscopy.

\subsection{Experiments from pure crystalline compounds}

For experiments starting from solid crystalline organic material an additional humidity cycle was needed to generate amorphous particles. Crystalline samples were placed in the environmental cell at room temperature and $0 \% \mathrm{RH}$. Water vapor was added until the RH levels reached $90 \%$ of the deliquescence RH of the crystalline compound and then the sample was cooled continuously at $0.1 \mathrm{~K} \mathrm{~min}^{-1}$ until deliquescence was observed. The resulting aqueous droplets were dried to $0 \% \mathrm{RH}$ and warmed to $298 \mathrm{~K}$ to create glassy particles. The sample was then subjected to a second humidity cycle to observe amorphous water uptake.

\section{Results and discussion}

\subsection{Deliquescence in crystalline versus amorphous particles}

Spectra and images obtained during a typical deliquescence experiment are shown in Fig. 1. This experiment began with a sample of crystalline citric acid monohydrate (deliquescence $\mathrm{RH}=77 \%$ at $298 \mathrm{~K}$, Salameh et al., 2005). As RH over the sample increased deliquescence was observed. The left panel in Fig. 1 presents a few of the spectra and images obtained during a crystalline deliquescence experiment at $252 \mathrm{~K}$. Water uptake is marked by the appearance of a broad O-H peak in the range of Raman frequencies associated with liquid water $\left(\sim 3100\right.$ and $\left.\sim 3600 \mathrm{~cm}^{-1}\right)$. This change is subtle due to overlapping peaks in this wavenumber range, therefore spectral subtraction was used to precisely determine onset conditions for water uptake. Spectral subtractions for this experiment are given in Appendix A, Fig. A1. In this experiment the crystalline deliquescence began at $76.2 \% \mathrm{RH}$ (Fig. 1, spectrum highlighted in blue). Deliquescence of the citric acid crystal proceeded over a small RH interval (76.2$79.5 \%$ ) as water was quickly absorbed into the bulk crystal. This transition was accompanied by clear changes in particle morphology as shown in the adjacent images. The newly formed liquid droplets were then dried to $0 \% \mathrm{RH}$ and warmed to room temperature to create glassy aerosol particles.

To demonstrate the distinct differences between crystalline and amorphous deliquescence, spectra obtained during the second humidity cycle, performed using the same (now glassy) particle are presented in Fig. 1 (right panel). The particle begins taking up water at much lower RH than it did during the first humidity cycle. The transition is again marked by the appearance of a peak at the characteristic Raman frequency for liquid water between 3100 and $3600 \mathrm{~cm}^{-1}$. The onset of water uptake in this example was observed at $30.9 \%$ $\mathrm{RH}$ and indicated by the small peak around $3400 \mathrm{~cm}^{-1}$ (Fig. 1, spectrum highlighted in red). Spectral subtraction results used to specifically determined the onset of water uptake are shown in Fig. A1. In contrast to deliquescence of the crystalline particle, water uptake on the glassy particle began at lower RH and proceeded gradually over a range of RH values as humidity was further increased. Additional spectra shown in this panel demonstrate how the particle continued to take up water over a large RH range (30.9-72.5\%, at a cooling rate of $0.1 \mathrm{~K} \mathrm{~min}^{-1}$ ). Optical images presented with these spectra show that hydration was not accompanied by a clear change in the size or structure of the amorphous (semi-)solid particle. Particle size did not significantly change as RH was increased up to $72.5 \%$. Water uptake during amorphous deliquescence can be kinetically hindered due to particle viscosity and may even be accompanied by particle shrinking due to microstructural rearrangements and the 

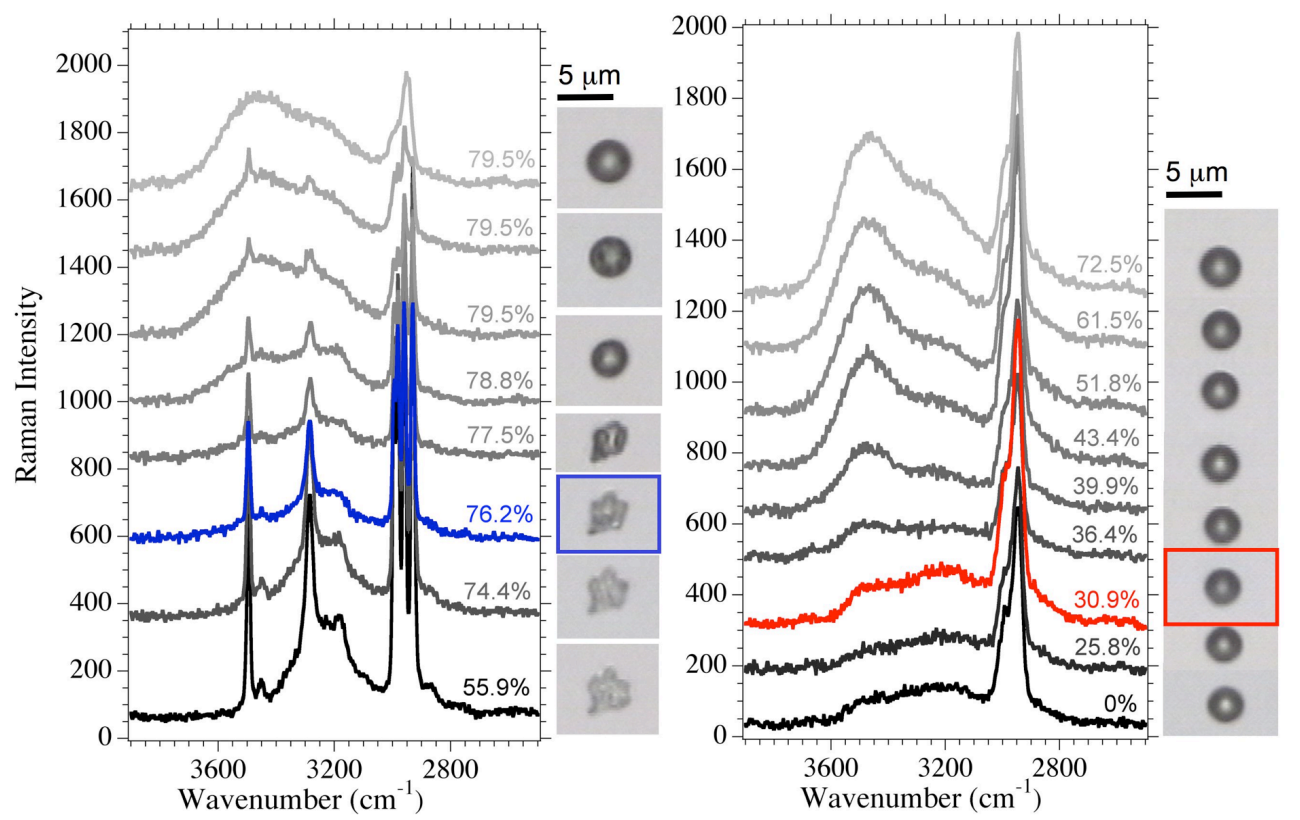

Fig. 1. Raman spectra and images demonstrating crystalline (left) and amorphous deliquescence (right) of a citric acid particle at 252 and $257 \mathrm{~K}$, respectively. The onset of water uptake for each experiment was determined using spectral subtraction and indicated by spectra highlighted in blue and red. Spectral subtractions are given in Appendix A, Fig. A1.

collapse of porous gel-like structures within the glassy particles (Mikhailov et al., 2009).

\subsection{State diagrams}

Results from water uptake experiments were used to create state diagrams as a function of temperature and RH for each species (Figs. 2-4). This type of diagram is useful for predicting aerosol phase over a wide range of atmospheric conditions. State diagrams include an ice melting curve $\left(T_{\mathrm{m}}\right)$, glass transition curve $\left(\mathrm{T}_{\mathrm{g}}\right)$ and homogeneous ice nucleation curve $\left(T_{\text {hom }}\right)$. $T_{\text {hom }}$ indicates where ice nucleation is expected to occur in liquid droplets based on the parameterization of Koop et al. (2000) assuming a homogeneous ice nucleation rate of $5 \times 10^{9} \mathrm{~cm}^{-3} \mathrm{~s}^{-1}$. This type of plot is referred to as a state diagram, rather than a phase diagram, because it includes both thermodynamically predicted phase transitions as well as kinetically controlled phase changes (Murray, 2008). The intersection point of $T_{\mathrm{m}}$ and $T_{\mathrm{g}}$ curves represents a unique point on each state diagram, known as $T_{\mathrm{g}}^{\prime}$ (Zobrist et al., 2008). $T_{\mathrm{g}}$, however, is strongly dependent on RH so all results from this study are reported as a function of $\mathrm{RH}$, using the notation $T_{\mathrm{g}}(\mathrm{RH})$.

The left panels in Figs. 2, 3 and 4, present state diagrams constructed based on experiments with sucrose, glucose and citric acid, respectively. All square markers correspond to experiments with pure organic species whereas triangles indicate the same transition for particles consisting of a 1:1 mixture of organic and ammonium sulfate. In all figures, open markers designate the onset of amorphous deliques- cence, black markers indicate that depositional ice nucleation was observed, and gray markers indicate that both water uptake and ice nucleation took place on separate particles. In other words, gray markers denote that within the same field of view, ice nucleation was observed on one particle while liquid water was detected on other particles using Raman spectroscopy. Experimental $T_{\mathrm{g}}(\mathrm{RH})$ and $T_{\mathrm{g}}(\mathrm{RH})_{\text {mix }}$ curves (red and blue) were generated by fitting third order polynomial equations to the experimental water uptake data for each organic and mixture. The fits have endpoints at the $T_{\mathrm{g}}$ of pure water $\left(\mathrm{RH}=100 \%, T_{\mathrm{g}}=136 \mathrm{~K}\right)$ at the low temperature extreme and correspond to experimentally determined $T_{\mathrm{g}}$ of each pure dry organic component (Bodsworth et al., 2010; Zobrist et al., 2008) at $0 \%$ RH. Fit parameters for each experimental $T_{\mathrm{g}}(\mathrm{RH})$ line presented in Figs. $2-4$ are listed in Appendix A, Table A1. For clarity, the portion of each curve corresponding to experimentally determined data is shown as a solid line and the section of each curve extrapolated to endpoints is dotted. Assuming equilibrium conditions, the region below (or to the right of) labeled $T_{\mathrm{g}}(\mathrm{RH})$ curves represents conditions under which aerosol particles were glassy. At temperatures and $\mathrm{RH}$ above (or to the left of) the $T_{\mathrm{g}}(\mathrm{RH})$ curves particles took up water and were liquid or semi-solid. Depending on particle viscosity, mass transfer of water into glassy or semi-solid aerosol can be extremely slow. Above the $T_{\mathrm{g}}(\mathrm{RH})$, however, water uptake is a self-accelerating process and micron-sized particles tend to equilibrate with the surrounding RH environment on timescales similar to the change in RH (10's to 100's of seconds) at room temperature 

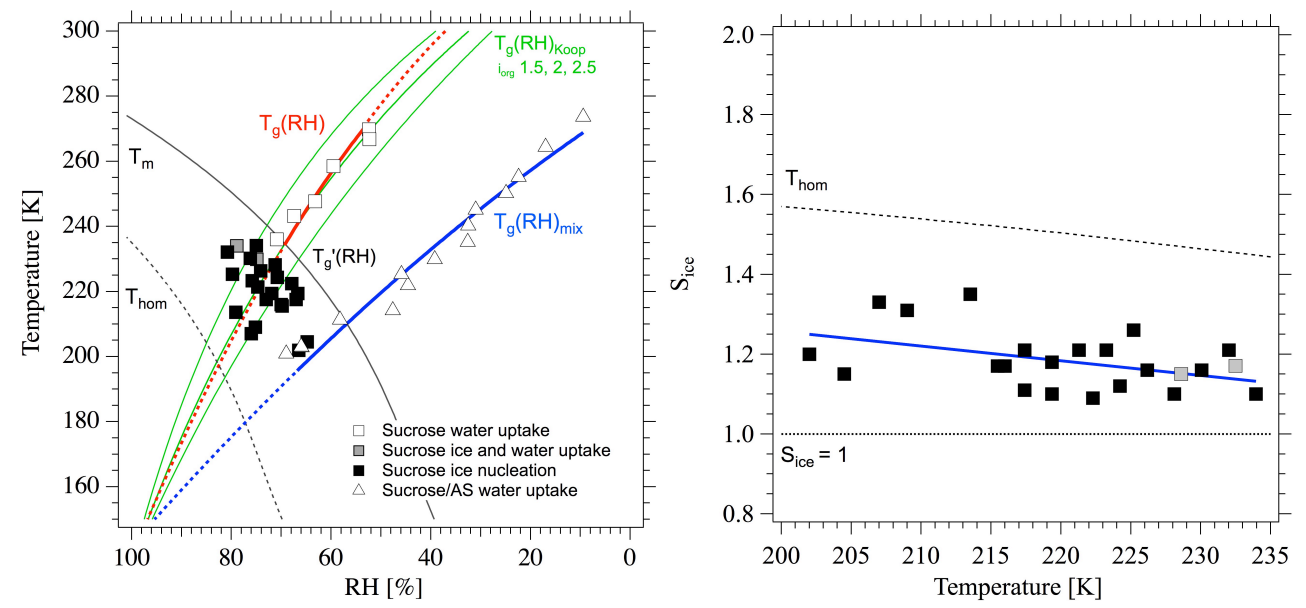

Fig. 2. State diagram for sucrose constructed using experimental data (left panel). $T_{\mathrm{g}}(\mathrm{RH})$ (red) and $T_{\mathrm{g}}(\mathrm{RH})_{\text {mix }}$ (blue) lines were created by fitting polynomial curves to experimental water uptake data. Green lines represent the theoretical RH dependence of $T_{\mathrm{g}}$ estimated following the method of Koop et al. (2011). $T_{\mathrm{g}}($ dry $)=335.7 \mathrm{~K}$ and $k_{\mathrm{GT}}=4.86$ were used to calculate $T_{\mathrm{g}}(\mathrm{RH})_{\text {Koop }}$ for van't Hoff factors $\left(i_{\text {org }}\right) 1.5$, 2 and 2.5. $T_{\mathrm{m}}$ is the ice melting curve and indicates where $S_{\text {ice }}=1$. Black markers represent experiments in which depositional ice nucleation was observed without water uptake. For experiments indicated by gray markers, ice nucleation was observed on one particle while liquid water was detected on other particles within the same field of view. The right panel gives ice saturation ratios as a function of temperature for each of the experiments in which ice nucleation was observed. $T_{\text {hom }}$ in both figures indicates where homogeneous ice nucleation would occur in liquid particles according to the parameterization of Koop et al. (2000) assuming a homogeneous ice nucleation rate of $5 \times 10^{9} \mathrm{~cm}^{-3} \mathrm{~s}^{-1}$. Fit parameters for experimental $T_{\mathrm{g}}(\mathrm{RH})$ curves are given in Appendix A, Table A1.
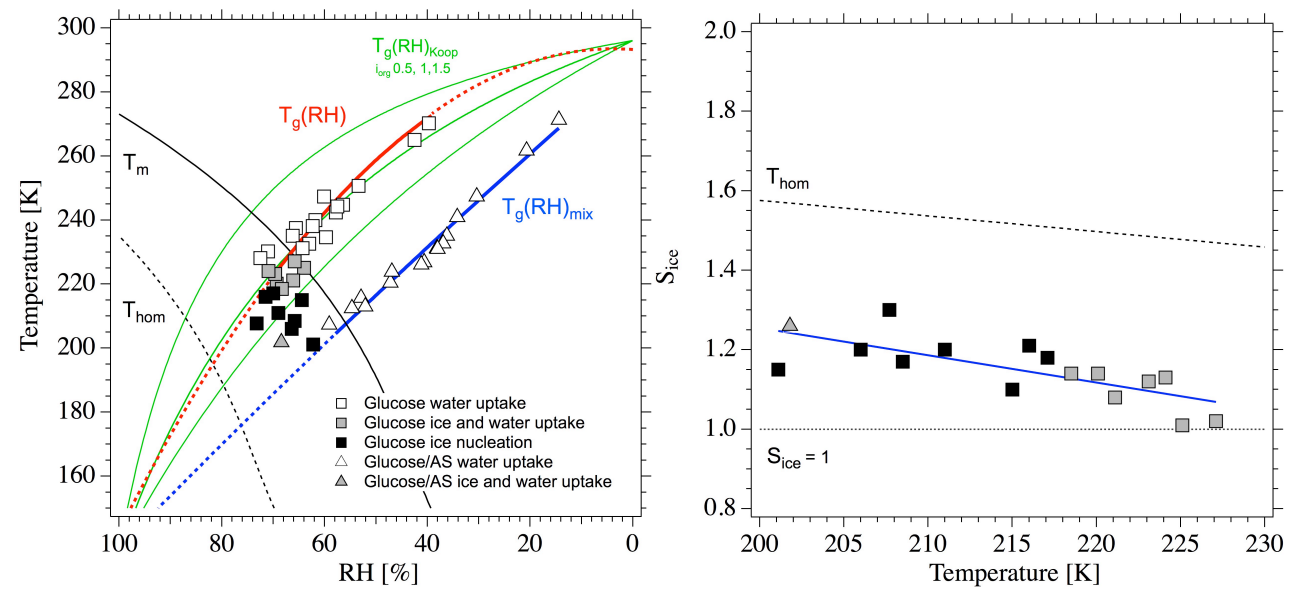

Fig. 3. State diagram and corresponding $S_{\text {ice }}$ plot for all experiments in which glucose or glucose/ammonium sulfate was investigated. Other symbols, lines and notation are the same as in Fig. 2. Glucose $T_{\mathrm{g}}(\mathrm{RH})_{\text {Koop }}$ curves (green) were calculated using $T_{\mathrm{g}}($ dry $)=296.1 \mathrm{~K}$ and $k_{\mathrm{GT}}=3.95$ for van't Hoff factors $\left(i_{\mathrm{org}}\right)$ 0.5, 1 and 1.5.

(Tong et al., 2011). Water vapor diffusion into glassy aerosol at low temperatures is significantly slower, but can be enhanced by orders of magnitude at increased RH (Zobrist et al., 2011).

Following the method of Wang et al. (2012a), timescales for water vapor diffusion into particles were estimated for pure sucrose particles to determine whether amorphous deliquescence could be expected to occur on experimentally and atmospherically relevant timescales. Sucrose has the highest $T_{\mathrm{g}}$ (dry) of the species investigated in this study and there- fore calculations represent an upper limit for the timescale of diffusion of water vapor into the particles examined. Formulations from Zobrist et al. (2011) were used to estimate the diffusion coefficient of water $\left(D_{\mathrm{H}_{2} \mathrm{O}}\right)$ into the particles for a range of conditions. Timescales for bulk diffusion into the particles were obtained following the methods of Shiraiwa et al. (2011) $\left(t=d^{2} / 4 \pi^{2} D_{\mathrm{H}_{2} \mathrm{O}}\right.$, where $t$ is time and $d$ is particle diameter). Finally, viscosity of the particles was estimated using the Stokes-Einstein equation, which relates particle viscosity and $D_{\mathrm{H}_{2} \mathrm{O}} . D_{\mathrm{H}_{2} \mathrm{O}}$ calculated at the onset of 

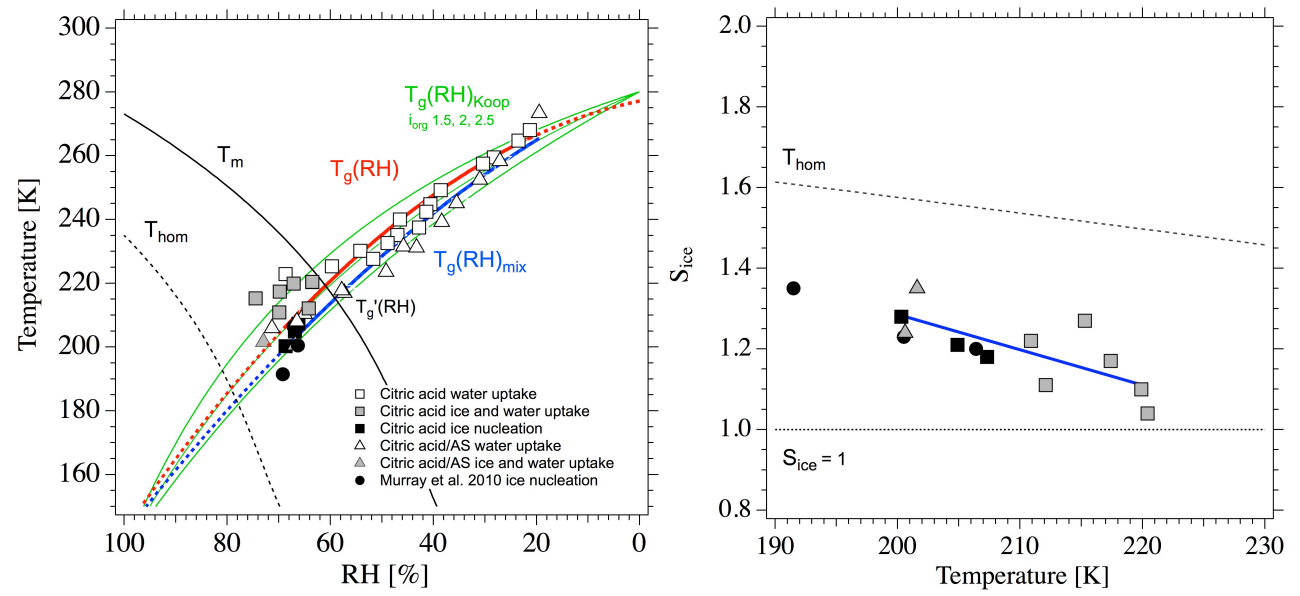

Fig. 4. State diagram and plot of ice saturation ratios for all water uptake and ice nucleation experiments performed on citric acid and citric acid/ammonium sulfate particles. Black circles in this figure represent ice nucleation on citric acid as observed during cloud chamber experiments from Murray et al. (2010). Other symbols, lines and notation are the same as in Fig. 2. Citric acid $T_{\mathrm{g}}(\mathrm{RH})_{\mathrm{Koop}}$ curves (green) were calculated using $T_{\mathrm{g}}(\mathrm{dry})=280.1 \mathrm{~K}$ and $k_{\mathrm{GT}}=3.18$ for van't Hoff factors $\left(i_{\mathrm{org}}\right) 1.5,2$ and 2.5 .

water uptake for experiments with pure sucrose was found to be on the order of $10^{-12} \mathrm{~cm}^{2} \mathrm{~s}^{-1}$ for all water uptake experiments $(T>236 \mathrm{~K})$. These diffusion coefficients correspond to timescales on the order of hundreds to thousands of seconds ( 8 to $34 \mathrm{~min}$ ) across the range of temperature and $\mathrm{RH}$ conditions for water uptake by $4 \mu \mathrm{m}$ sucrose particles. These results indicate that at humidified conditions amorphous deliquescence of the particles could have occurred on timescales relevant for aerosol processing in clouds. Viscosities derived at the onset of water uptake for sucrose were all in the semisolid regime, on the order of $10^{3} \mathrm{Pas}$. Bones et al. (2012) have demonstrated that Stokes-Einstein can be used to reasonably predict the viscosity of sucrose particles between 1 and $10^{4} \mathrm{~Pa}$ s. Still, viscosities reported here should be considered estimates as the Stokes-Einstein equation may not hold for concentrated species near $T_{\mathrm{g}}(\mathrm{RH})$.

Comparing the state diagrams constructed for each organic species, pure sucrose $\left(T_{\mathrm{g}}^{\prime}(\mathrm{RH})=236 \mathrm{~K}\right.$, Fig. 2$)$ has the highest $T_{\mathrm{g}}^{\prime}(\mathrm{RH})$ of the six systems investigated here. At temperatures ranging from 235 to $270 \mathrm{~K}$, sucrose particles (open squares) did not begin taking up water until 54-71\% RH. Over the same temperature range, glucose $\left(T_{\mathrm{g}}^{\prime}(\mathrm{RH})=230 \mathrm{~K}\right.$, Fig. 3, open squares) began taking up water at between 40 $72 \% \mathrm{RH}$ and citric acid $\left(T_{\mathrm{g}}^{\prime}(\mathrm{RH})=220 \mathrm{~K}\right.$, Fig. 4, open squares) from $22-68 \% \mathrm{RH}$. One consequence of a lower $T_{\mathrm{g}}^{\prime}(\mathrm{RH})$ is that citric acid particles were aqueous or semisolid over a wider range of conditions than the other two organic substances. Sucrose particles, on the other hand, remained glassy until much higher humidity levels.

\subsection{Comparison of $T_{\mathrm{g}}(\mathrm{RH})$ results to other studies}

Zobrist et al. (2011) investigated water uptake by amorphous sucrose particles using an electrodynamic balance. At $291 \mathrm{~K}$ and $\mathrm{dRH} / \mathrm{d} T=0.05 \% \mathrm{~min}^{-1}$, they observed a moistureinduced phase transition in a micron-sized glassy sucrose particle starting at $\mathrm{RH}=35 \%$ with substantial water uptake (considered the transition to liquid phase) by $\mathrm{RH}=$ $40 \%$. Additional calorimetry experiments supported the fact that the particle was glassy below $\sim 31 \%$ RH. For a humidity ramp rate of $1 \% \mathrm{~min}^{-1}$, similar to the rate employed in the present study, Zobrist et al. (2011) observed the glassto-liquid transition at $53 \% \mathrm{RH}$, which is in good agreement with sucrose results presented in this manuscript. The study by Zobrist et al. (2011) highlights the fact that water uptakes obtained using the Raman technique may represent an upper limit because RH for the onset of water uptake is expected to decrease as the humidification rate is decreased towards zero (full equilibrium conditions).

Using the semi-empirical method outlined in Koop et al. (2011), the theoretical RH dependence of $T_{\mathrm{g}}$ was estimated for each pure organic compound used in this study. Equation (1) was used to calculate water activity $\left(a_{\mathrm{w}}\right)$ as a function of van't Hoff factor $\left(i_{\text {org }}\right)$ and number of moles of water $\left(n_{\mathrm{w}}\right)$ and solute $\left(n_{\mathrm{org}}\right)$.

$a_{\mathrm{w}}=\left(1+i_{\text {org }} \frac{n_{\text {org }}}{n_{\mathrm{w}}}\right)^{-1}$

The Gordon-Taylor approach along with experimentally determined $T_{\mathrm{g}}(\mathrm{dry})$ values and system-specific Gordon-Taylor constants $\left(k_{\mathrm{GT}}\right)$ from Lienhard et al. (2012) and Zobrist et al. (2008) were used to calculate $T_{\mathrm{g}}$ for solute concentrations from 0 to 1 . Assuming equilibrium conditions, derived $T_{\mathrm{g}}$ versus RH values are plotted using constant values for $i_{\text {org }}$ between 0.5 and 2.5. Theoretical $T_{\mathrm{g}}(\mathrm{RH})$ curves calculated according this method are shown along with experimental data in Figs. 2, 3, and 4 (green lines) for each pure organic 
compound. Examination of these figures show that theoretical $T_{\mathrm{g}}(\mathrm{RH})$ swathes calculated using the Koop et al. (2011) approach are in good agreement with the experimental data presented. This supports the hypothesis that water uptake may be related to $T_{\mathrm{g}}(\mathrm{RH})$. Polynomial curves that were fitted to experimental data are also similar to theoretical $T_{\mathrm{g}}(\mathrm{RH})$ swathes.

Figure 5 shows $T_{\mathrm{g}}(\mathrm{RH})$ curves estimated by Koop et al. (2011) using this same method for a range of atmospheric SOA particles. It can be seen that our experimental data for the pure and mixed organics fit within the Koop parameterization. Thus, the organics and mixtures used in this study are expected to be good proxies for atmospheric SOA.

Wang et al. (2012a) measured the onset of water uptake for laboratory proxies and ambient SOA particles using optical microscopy for detection of water uptake. For compounds with similar $\mathrm{O}: \mathrm{C}$ ratios as those investigated in the present work, they found higher water uptake onsets $(\sim 85 \% \mathrm{RH}$ at $240 \mathrm{~K})$. The difference could be due to the specific organics investigated, particle size or due to different detection methods for the onset of water uptake. Although the Wang et al. (2012a) data is at the upper end of the Koop et al. parameterization, their data also falls within the Koop et al. SOA range.

\subsection{Influence of ammonium sulfate on the $T_{\mathrm{g}}(\mathrm{RH})$ of organic aerosol particles}

Direct measurements of aerosol composition near the TTL region suggest the majority of particles consist of partially or fully neutralized sulfate mixed with oxygenated organics (Froyd et al., 2010). Froyd et al. (2010) further reported the mass fraction of organic material in the sampled background aerosol was often $>50 \%$. Thus, it is likely that the experiments performed with organic-sulfate mixtures better represent the behavior of atmospheric particles found in the TTL.

Triangles in each state diagram show results from experiments with aerosol particles consisting of $1: 1$ internal mixtures of organic material and ammonium sulfate. In every case, the addition of ammonium sulfate shifts the $T_{\mathrm{g}}(\mathrm{RH})$ curve of the organic substance towards lower $T_{\mathrm{g}}^{\prime}(\mathrm{RH})$ values. This type of shift was anticipated because inorganic species tend to have lower $T_{\mathrm{g}}$ than organic species and will act as plasticizers, reducing the viscosity of a mixture compared to that of a pure compound (Saukko, 2012; Wilson et al., 2012; Zobrist et al., 2008; Koop et al., 2011). In the present study ammonium sulfate always lowers $T_{\mathrm{g}}(\mathrm{RH})$ but does not seem to affect all of the organic substances to the same degree. For example, the ammonium sulfate has little effect on the $T_{\mathrm{g}}^{\prime}(\mathrm{RH})$ of citric acid but lowers the $T_{\mathrm{g}}^{\prime}(\mathrm{RH})$ of both sucrose and glucose by more than $20 \mathrm{~K}$. In every system studied, the addition of ammonium sulfate shifts $T_{\mathrm{g}}(\mathrm{RH})$ towards lower $\mathrm{RH}$, so that aerosol particles are liquid over a larger range of temperatures and RHs. The variable influence of ammonium sulfate on the $T_{\mathrm{g}}(\mathrm{RH})$ of these organic compounds implies

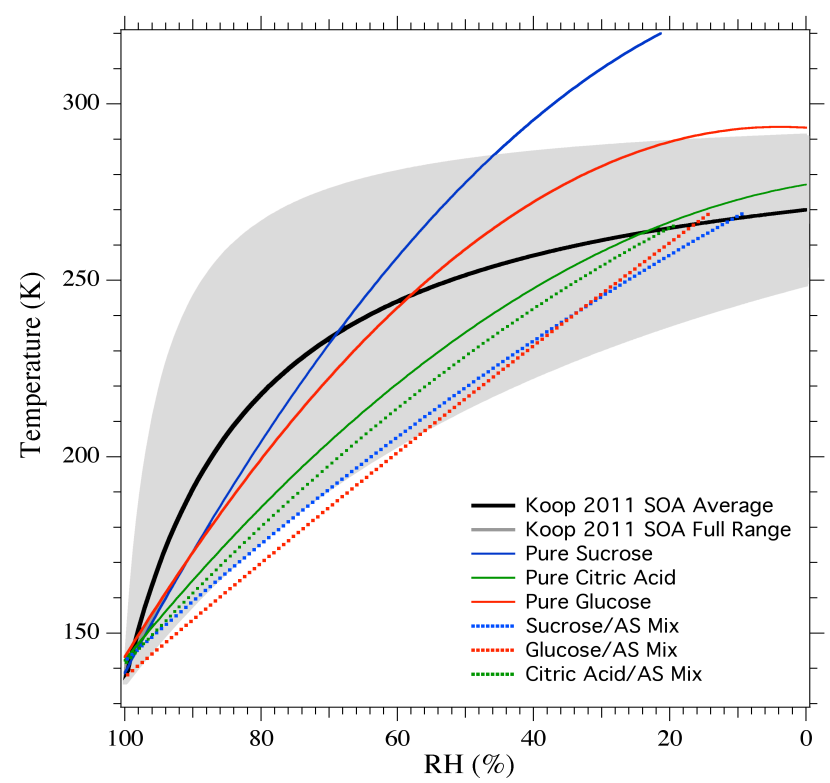

Fig. 5. State diagram depicting experimentally determined $T_{\mathrm{g}}(\mathrm{RH})$ curves from this study and the estimated range of $T_{\mathrm{g}}(\mathrm{RH})$ for atmospheric SOA from Koop et al. (2011). This plot indicates that the organics and mixtures investigated in this study may be good proxies for atmospheric SOA.

that the range of possible conditions under which organic aerosol will be glassy in the upper troposphere is dependent on chemical composition, particle morphology and mixing state of the aerosol in addition to temperature, RH and dynamics.

\subsection{Ice nucleation from amorphous (semi-)solid aerosol}

For each organic discussed above, there are certain conditions under which heterogeneous ice nucleation was observed. Ice formation was observed during experiments indicated by either black or gray markers on each plot in Figs. 2, 3 and 4. Black markers denote depositional ice nucleation on glassy particles, whereas gray points indicate that both water uptake and heterogeneous ice nucleation were observed at nearly the same time on separate particles. Onset conditions for ice nucleation have been included as part of each state diagram and are also given as a function of $S_{\text {ice }}$ in the right panel in Figs. 2, 3 and 4.

At the lowest temperatures, ice nucleation on glassy particles prior to water uptake (black markers in every figure) was typically observed. This depositional mode ice nucleation oc-

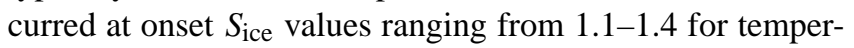
atures of 235 to $200 \mathrm{~K}$. For sucrose experiments the average $S_{\text {ice }}$ was $1.19 \pm 0.08$, which is not significantly different than the same metric for citric acid $\left(S_{\text {ice, ave }}=1.18 \pm 0.08\right)$ or glucose $\left(S_{\text {ice, ave }}=1.14 \pm 0.07\right)$ at temperatures below $235 \mathrm{~K}$. 
The results for depositional mode ice nucleation presented in this manuscript are similar to results from previous studies of ice nucleation using laboratory-generated proxies or ambient SOA. Saturation ratios for depositional ice nucleation on these species are in excellent agreement with results from Murray et al. (2010), who examined ice nucleation on glassy citric acid aerosol $(\sim 150 \mathrm{~nm})$ (Fig. 4, black circles, $T=190-207 \mathrm{~K})$. Wilson et al. (2012) observed depositional freezing onsets between $S_{\text {ice }}=1.2-1.6(T<200 \mathrm{~K})$ in cloud chamber experiments with raffinose, 4-hydroxy-3methoxy-DL-mandelic acid, levoglucosan and a multicomponent organic/sulfate mixture. Similarly, ice saturation ratios near $200 \mathrm{~K}$ of $1.18<S_{\text {ice }}<1.57$ were reported by Schill and Tolbert (2012a) for depositional nucleation on monocarboxylic films.

For experiments with laboratory-generated solid/glassy naphthalene SOA, Wang et al. (2012a) reported depositional ice nucleation with mean ice onsets between $S_{\text {ice }}=1.35$ and 1.52 at $T<230 \mathrm{~K}$. Although mean ice onsets from Wang et al. (2012a) were generally higher than those observed in the present study, for several individual experiments ice onsets as low as $S_{\text {ice }}=1.23$ were observed. Anthropogenic aerosol containing a high fraction of organic material collected near Mexico City heterogeneously nucleated ice at $S_{\text {ice }}$ between $\sim 1.15$ and 1.5 at $T<230 \mathrm{~K}$ (Knopf et al., 2010). Wang et al. (2012b) found similar results for organic-rich aerosol samples collected in both Los Angeles and Mexico City. For depositional ice nucleation, lower freezing onsets will generally be observed for samples with higher total particle surface area due to the increased probability of a highly efficient ice nucleation active site in the sample. Therefore, total exposed surface area of aerosol could account for differences in observed ice onsets for the various studies described here.

For experiments indicated by gray markers, both water uptake and ice were observed at nearly the same time on separate particles within the same field of view. Depending on whether IN particles were wet prior to ice formation, heterogeneous freezing may have occurred either by deposition or immersion modes. Using the Raman experimental setup it was not possible to determine whether water uptake occurred prior to ice formation in these cases and therefore we cannot rule out either freezing mechanism. These processes were only observed in tandem for particular experimental conditions. Specifically, when RH levels for water uptake and ice formation were similar. Thus it is possible that we were observing a competition between water uptake and ice formation processes. A similar phenomenon was observed by Wise et al. (2012) when investigating deliquescence and ice nucleation of $\mathrm{NaCl}$ hydrates. $S_{\text {ice }}$ for the onset of ice nucleation in these experiments was always lower than $T_{\text {hom }}$, which rules out a homogeneous freezing pathway. At higher or lower experimental temperatures either water uptake or ice formation clearly dominates and this effect is not observed. The points have been given their own color (gray) to make it clear that results were distinct for these experiments.
The temperature at which ice nucleation was first observed either with or without water uptake for each system was 234, 227 and $220 \mathrm{~K}$ for sucrose, glucose and citric acid, respectively. In these experiments onset freezing temperature trended with both $T_{\mathrm{g}}($ dry $)$ and $\mathrm{O}: \mathrm{C}$ ratio of the pure organic compounds (Sucrose $T_{\mathrm{g}}(\mathrm{dry})=335.7 \mathrm{~K}, \mathrm{O}: \mathrm{C}=$ 0.92; Glucose $T_{\mathrm{g}}$ (dry) $=296.1 \mathrm{~K}, \mathrm{O}: \mathrm{C}=1.0$; Citric Acid $T_{\mathrm{g}}($ dry $)=280.1 \mathrm{~K}, \mathrm{O}: \mathrm{C}=1.17$, Bodsworth et al., 2010; Zobrist et al., 2008) but did not strictly follow molar mass (Sucrose $342.3 \mathrm{~g} \mathrm{~mol}^{-1}$; Glucose $180.16 \mathrm{~g} \mathrm{~mol}^{-1}$, Citric Acid $192.12 \mathrm{~g} \mathrm{~mol}^{-1}$ ). O : C ratios for these three organic compounds span only a small range so it is not likely to explain the difference in onset freezing temperatures for these experiments. Wang et al. (2012a) who investigated organic compounds with a wide range of $\mathrm{O}: \mathrm{C}$ ratios observed depositional ice nucleation onsets independent of $\mathrm{O}: \mathrm{C}$ ratio.

In summary, we find that glassy organic aerosol can act as suitable surfaces for ice formation. Heterogeneous ice nucleation always proceeded at saturation ratios lower than the homogeneous nucleation threshold. The average $S_{\text {ice }}$ for all systems studied here was $\sim 1.2$ versus $S_{\text {ice }}=1.5-1.6$ for homogeneous nucleation when $T<235 \mathrm{~K}$.

\subsection{Ice nucleation on internally mixed organic-sulfate particles}

Ice residues from subvisible cirrus often consist of organic/sulfate mixtures (average organic weight fraction $64 \%$, Froyd et al., 2010) and some ice crystals are believed to form via a heterogeneous nucleation process. To help explain these observations, ice nucleation experiments were also conducted using internally mixed organicsulfate particles. In this study, heterogeneous ice nucleation events were rarely observed on organic-sulfate particles at $T>200 \mathrm{~K}$. $T_{\mathrm{g}}^{\prime}(\mathrm{RH})$ of sucrose/ammonium sulfate samples was depressed by $26 \mathrm{~K}$ compared to the pure organic. Mixed sucrose/ammonium sulfate particles took up water prior to ice nucleation over the entire range of temperatures investigated in this study $\left(T_{\mathrm{g}}(\mathrm{RH})_{\text {mix }}\right.$ and open triangles, Fig. 2) and ice nucleation was never observed. For both citric acid and glucose mixed with ammonium sulfate, ice nucleation was only observed along with water uptake in a few experiments (gray triangles, Figs. 3, 4) near the experimental limit of $\sim 200 \mathrm{~K}$. The range of $S_{\text {ice }}$ values for the onset of nucleation in these few experiments was, however, similar to those observed for the pure organic glasses. This mechanism could therefore help explain heterogeneous ice formation in subvisible cirrus that are ever-present near the TTL $(T \sim 180$ $200 \mathrm{~K})$. 


\subsection{Inhibition of ammonium sulfate efflorescence in internally mixed particles}

Ammonium sulfate solution droplets have been studied by many groups and efflorescence is known to occur at $\sim 35 \%$ RH independent of temperature (e.g., Bodsworth et al., 2010; and Martin, 2000). At low temperatures efflorescence of ammonium sulfate may however be suppressed or eliminated in internal mixtures with high weight fractions of organic material (Bodsworth et al., 2010). During experiments in the present study, crystallization was not observed in either organic or sulfate components of internally mixed particles. Several samples of internally mixed particles were exposed to $0 \% \mathrm{RH}$ for more than $24 \mathrm{~h}$ and efflorescence was never observed. Due to high viscosity of the glassy organic material crystallization of the ammonium sulfate was eliminated. This observation supports results from Bodsworth et al. (2010) who demonstrated that the addition of citric acid lowered the efflorescence RH, or in moderate concentrations at cold temperatures (i.e., 0.3 mole fraction at $T<250 \mathrm{~K}$ ), completely eliminated efflorescence in ammonium sulfate. The data presented here, also supports their conclusion that the literature efflorescence value for pure ammonium sulfate cannot always be used to predict conditions under which solid ammonium sulfate will exist in upper tropospheric aerosol.

\section{Atmospheric implications}

Experimental results have demonstrated that glassy organic aerosol particles can serve as heterogeneous IN at tropospheric conditions. In the atmosphere, particle phase will depend on air parcel history and dynamics in addition to temperature, RH and particle composition. Currently it is not known whether glassy aerosol particles are available for ice nucleation in the upper troposphere.

To estimate the relative importance of a heterogeneous mechanism for tropospheric ice formation on glassy aerosol, a model was used to estimate the fraction of time glassforming SOA particles similar to investigated proxies would be glassy in the upper troposphere. The model CARMA was employed following the same approach as Jensen et al. (2010). Temperature, RH, $S_{\text {ice }}$ and aerosol phase were monitored along a large number of TTL and midlatitude air parcel trajectories. During model simulations, a large collection of diabatic back trajectories were launched at $82.6 \mathrm{hPa}$ on a regular grid throughout the tropics and midlatitude upper troposphere every week for a year. Trajectories were run backward 90 days or until they hit convection. Only the subset of trajectories that hit convection prior to the 90 day limit were used in this study. The model was then run forward in time from the point of convective encounter to the starting point of the trajectories. At the time of convective detrainment it was assumed that $S_{\text {ice }}=1$, which set the initial water vapor concentration in the parcel. If $S_{\text {ice }}$ exceeded 1.30, par- cel water vapor concentration was reduced to ice saturation. This gave RH along each trajectory. From there, the fraction of time that parcel conditions were above/below $T_{\mathrm{g}}(\mathrm{RH})$ was used to predict the fraction of time particles would be glassy. Fraction of time reflects the percentage of time an average particle was glassy following an air parcel along its trajectory. All particles were initially considered aqueous and remained so until parcel $T$ and RH changed such that a glass transition would be expected. This method assumes that every particle forms a glass below $T_{\mathrm{g}}(\mathrm{RH})$ and that crystallization never occurs. Experimentally determined $T_{\mathrm{g}}(\mathrm{RH})$ curves for each species and mixture from this study were used to define particle state based on air parcel conditioning in the model. To extend results beyond the organic species investigated in this study, the model was also run using the full range of $T_{\mathrm{g}}(\mathrm{RH})$ values estimated for atmospheric SOA by Koop et al. (2011). Results from all model trajectories were averaged and used to estimate the fraction of time particles are expected to be glassy given conditioning in the TTL $(185 \mathrm{~K}<T<220 \mathrm{~K})$ and midlatitude upper troposphere $(215 \mathrm{~K}<T<235 \mathrm{~K})$.

Figure 6 shows the fraction of time that glass-forming organic/SOA aerosol particles are expected to be glassy at typical midlatitude (left) and TTL (middle) conditions. Solid/colored lines in each figure correspond to results for pure organic species whereas colored/dashed lines indicate results for organic-sulfate mixed aerosol. Koop High, Low and Mid lines correspond to the high, low and average expected $T_{\mathrm{g}}(\mathrm{RH})$ for atmospheric SOA based on Koop et al. (2011) (depicted in Fig. 5). The fraction of time particles are predicted to be glassy for midlatitude conditions is greater than $60 \%$ for every particle type. Despite higher temperatures in the midlatitude upper troposphere, the fraction of time particles will be glassy is overall higher compared to the TTL. This is due to generally higher RH levels found at tropical latitudes. In the TTL, every particle type is predicted to be glassy more than $40 \%$ of the time. Results for the lower TTL show greater variability because convective detrainment hydrates the air, lowering the glass fraction due to moistureinduced particle phase transitions. The fraction of time that aerosol is predicted to be glassy approaches $100 \%$ for all investigated scenarios at temperatures near and below $200 \mathrm{~K}$. It is clear from these results that organic aerosol subjected to conditions typical of both the midlatitude upper troposphere and TTL regions will likely spend a significant amount of the time in a glassy state. This will, in turn, influence aerosol chemistry, aerosol radiative properties and cloud condensation nuclei activity.

The same model was also used to determine whether glassy aerosol would be available to serve as heterogeneous IN at conditions conducive for ice nucleation (i.e., when $\left.S_{\text {ice }}>1.0\right)$. For this type of run the initial $S_{\text {ice }}$ minimizes the glassy fraction because a significant portion of the aerosol will take up water at RH levels on the way to ice saturation. By subsetting the data for $S_{\text {ice }}>1$, there is generally higher 

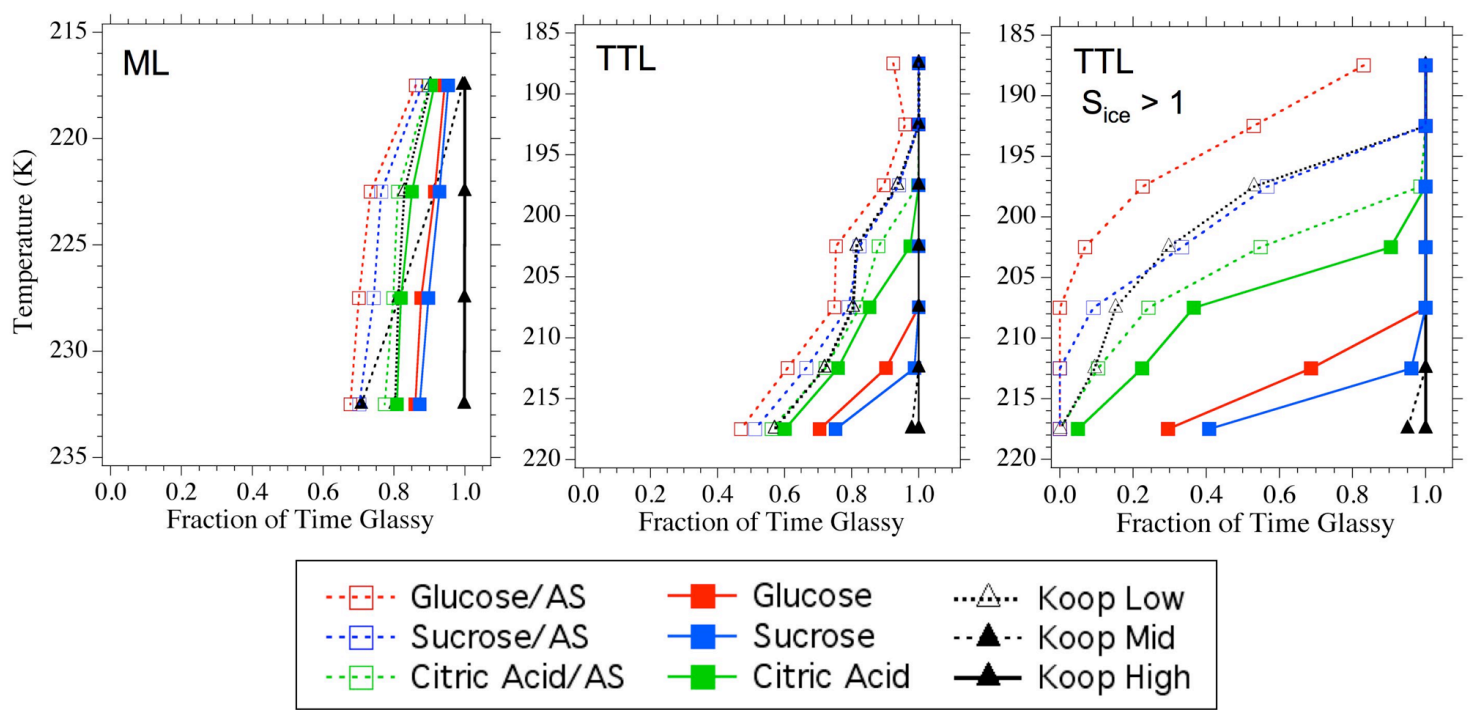

Fig. 6. Fraction of time that organic and mixed organic-ammonium sulfate (AS) particles are predicted to be glassy for midlatitude upper troposphere (ML) and TTL conditions (left and middle panels). Modeled results spanning the range of $T_{\mathrm{g}}(\mathrm{RH})$ values predicted for atmospheric SOA by Koop et al. (2011) are also included in black. The right panel shows the fraction of time aerosol of each type will be glassy at TTL conditions favorable for ice formation $\left(S_{\text {ice }}>1\right)$.

parcel RH and so the aerosol is more likely to be liquid or semi-solid in phase for the "ice nucleation" scenario. For midlatitude "ice nucleation" trajectories (not shown here), the fraction of time aerosol was glassy remained nearly zero for all cases except pure sucrose, glucose and Koop SOA with the highest $T_{\mathrm{g}}(\mathrm{RH})$. Results from the TTL "ice nucleation" scenario are shown in Fig. 6 (right panel). At warmer temperatures the glass fraction ranges widely, suggesting that particle composition and/or $T_{\mathrm{g}}(\mathrm{RH})$ will strongly influence the fraction of the time it is glassy in the lower TTL. At temperatures below $200 \mathrm{~K}$ and $S_{\text {ice }}>1$, pure organic aerosol and SOA with average to high $T_{\mathrm{g}}$ (dry) was glassy nearly $100 \%$ of the time, independent of aerosol composition. With the exception of the glucose/sulfate particles, internally mixed particles were glassy more than $\sim 50 \%$ of the time at $200 \mathrm{~K}$. These results suggest that at conditions conducive to ice formation in the TTL particles consisting of organics, organic/sulfate mixtures or SOA are likely to be glassy a significant portion of the time. Therefore heterogeneous ice nucleation on glassy aerosol could be an important mechanism for subvisible cirrus formation in the TTL.

\section{Conclusions}

In this manuscript results were presented for water uptake and heterogeneous ice nucleation on samples of pure and internally mixed glassy organic aerosol over a wide range of atmospherically relevant conditions. Experimental results were used to construct $T_{\mathrm{g}}(\mathrm{RH})$ curves for sucrose, glucose, citric acid and mixtures with ammonium sulfate based on moisture-induced phase transitions in the aerosol particles. Results from experiments with mixed organic-sulfate particles demonstrate the importance of aerosol mixing state for predicting partitioning between the phase states of organic aerosol. Pure organic particles and species with higher $T_{\mathrm{g}}$ (dry) values, such as sucrose, are more likely to remain in glassy state over a larger range of atmospheric conditions.

Internally mixed organic-sulfate particles with a high weight fraction $(>50 \%)$ of organic material will exist as aqueous solutions a larger fraction of the time than pure organic aerosol of the same composition. For internally mixed particles, amorphous organic material was also observed to suppress efflorescence of ammonium sulfate.

Partitioning between organic aerosol phase states will in turn dictate the pathway(s) available for ice nucleation and influence water uptake. Results presented from the CARMA model have shown that glassy organic aerosol particles are likely present in both the midlatitude upper troposphere and TTL regions. At temperatures $<200 \mathrm{~K}$, such as those found in the TTL region, a pathway for heterogeneous ice formation on both organic and mixed organic-sulfate aerosol particles is likely available. When glassy aerosol is present, experimental results predict ice formation via heterogeneous nucleation at ice saturation ratios between $\sim 1.2-1.4$. 
Appendix A
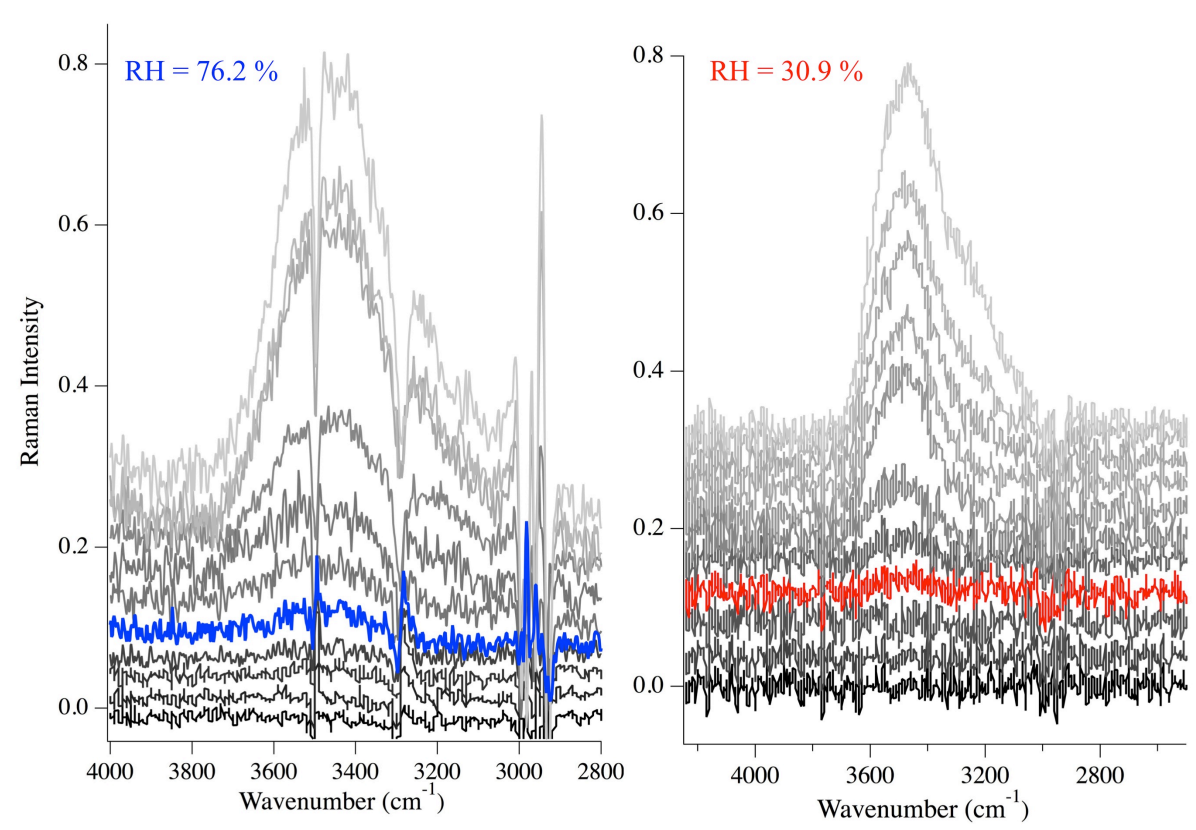

Fig. A1. Spectral subtractions corresponding to experiments shown in Fig. 1 demonstrate growth of the Raman O-H stretching peak (3100$3600 \mathrm{~cm}^{-1}$ ) associated with liquid water uptake during crystalline (left) and amorphous (right) deliquescence experiments with citric acid. Onset of water uptake is observed in highlighted spectra (blue and red), which correspond to onset RHs of $76.2 \%$ for crystalline deliquescence and $30.9 \%$ for amorphous deliquescence.

Table A1. Fit parameters for $T_{\mathrm{g}}(\mathrm{RH})$ lines for all investigated aqueous organic glasses and mixtures. $Y=A+B X+C X^{2}$, where $X$ is humidity from $0-100 \%$ and $Y$ is temperature in Kelvin. Parameters are listed along with uncertainties at the one standard deviation level.

\begin{tabular}{lrrrr}
\hline Substances & $A$ & $B$ & $C$ & $R^{2}$ \\
\hline Sucrose & $333.94 \pm 4.89$ & $-0.30 \pm 0.18$ & $-0.017 \pm 0.0017$ & 0.99 \\
Sucrose/AS & $278.53 \pm 5.47$ & $-0.99 \pm 0.23$ & $-0.0037 \pm 0.0021$ & 0.98 \\
Glucose & $293.26 \pm 5.61$ & $0.12 \pm 0.19$ & $-0.016 \pm 0.0019$ & 0.97 \\
Glucose/AS & $288.91 \pm 4.01$ & $-1.39 \pm 0.15$ & $-0.0013 \pm 0.0013$ & 0.99 \\
Citric Acid & $277.14 \pm 4.66$ & $-0.33 \pm 0.18$ & $-0.010 \pm 0.0018$ & 0.97 \\
Citric Acid/AS & $282.59 \pm 8.99$ & $-0.75 \pm 0.33$ & $-0.0066 \pm 0.0028$ & 0.97 \\
\hline
\end{tabular}

Acknowledgements. This work was supported by the National Science Foundation (ATM0650023 and AGS1048536). Also thanks to T. W. Wilson, T. Koop, D. Knopf and D. J. O'Sullivan for useful discussions and advice during the preparation of this manuscript.

Edited by: B. Ervens

\section{References}

Angell, C. A.: Formation of Glasses From Liquids and Biopolymers, Science, 267, 1924-1935, doi:10.1126/science.267.5206.1924, 1995.

Baustian, K. J., Wise, M. E., and Tolbert, M. A.: Depositional ice nucleation on solid ammonium sulfate and glutaric acid particles, Atmos. Chem. Phys., 10, 2307-2317, doi:10.5194/acp-10-2307$2010,2010$.
Bodsworth, A., Zobrist, B., and Bertram, A. K.: Inhibition of efflorescence in mixed organic-inorganic particles at temperatures less than 250 K, Phys. Chem. Chem. Phys., 12, 12259-12266, doi:10.1039/c0cp00572j, 2010.

Bones, D. L., Reid, J. P., Lienhard, D. M., and Krieger, U. K.: Comparing the mechanism of water condensation and evaporation in glassy aerosol, P. Natl. Acad. Sci. USA, 109, 11613-11618, doi:10.1073/pnas.1200691109, 2012.

Buck, A. L.: New equations for computing vapor-pressure and enhancement factor, J. Appl. Meteorol., 20, 1527-1532, 1981.

Cappa, C. D. and Wilson, K. R.: Evolution of organic aerosol mass spectra upon heating: implications for OA phase and partitioning behavior, Atmos. Chem. Phys., 11, 1895-1911, doi:10.5194/acp11-1895-2011, 2011.

Cziczo, D. J., DeMott, P. J., Brooks, S. D., Prenni, A. J., Thomson, D. S., Baumgardner, D., Wilson, J. C., Kreidenweis, S. 
M., and Murphy, D. M.: Observations of organic species and atmospheric ice formation, Geophys. Res. Lett., 31, L12116, doi:10.1029/2004g1019822, 2004.

Debenedetti, P. G. and Stillinger, F. H.: Supercooled liquids and the glass transition, Nature, 410, 259-267, doi:10.1038/35065704, 2001.

Forster, P., Ramaswamy, V., Artaxo, P., Berntsen, T., Betts, R., Fahey, D. W., Haywood, J., Lean, J., Lowe, D. C., Myhre, G., Nganga, J., Prinn, R., Raga, G., Schulz, M., and Van Dorland, R.: Changes in Atmospheric Constituents and in Radiative Forcing, in: Climate Change 2007: The Physical Science Basis. Contribution of Working Group I to the Fourth Assessment Report of the Intergovernmental Panel on Climate Change, edited by: Solomon, S., Qin, D., Manning, M., Chen, Z., Marquis, M., Averyt, K. B., Tignor, M., and Miller, H. L., Cambridge University Press, Cambridge, 131-234, 2007.

Froyd, K. D., Murphy, D. M., Lawson, P., Baumgardner, D., and Herman, R. L.: Aerosols that form subvisible cirrus at the tropical tropopause, Atmos. Chem. Phys., 10, 209-218, doi:10.5194/acp10-209-2010, 2010.

Graham, B., Guyon, P., Taylor, P. E., Artaxo, P., Maenhaut, W., Glovsky, M. M., Flagan, R. C., and Andreae, M. O.: Organic compounds present in the natural Amazonian aerosol: Characterization by gas chromatography-mass spectrometry, J. Geophys. Res.-Atmos., 108, 4766, doi:10.1029/2003jd003990, 2003.

Jensen, E. J., Pfister, L., Bui, T.-P., Lawson, P., and Baumgardner, D.: Ice nucleation and cloud microphysical properties in tropical tropopause layer cirrus, Atmos. Chem. Phys., 10, 1369-1384, doi:10.5194/acp-10-1369-2010, 2010.

Kärcher, B. and Ström, J.: The roles of dynamical variability and aerosols in cirrus cloud formation, Atmos. Chem. Phys., 3, 823838, doi:10.5194/acp-3-823-2003, 2003.

Knopf, D. A., Wang, B., Laskin, A., Moffet, R. C., and Gilles, M. K.: Heterogeneous nucleation of ice on anthropogenic organic particles collected in Mexico City, Geophys. Res. Lett., 37, L11803, doi:10.1029/2010g1043362, 2010.

Koop, T., Luo, B. P., Tsias, A., and Peter, T.: Water activity as the determinant for homogeneous ice nucleation in aqueous solutions, Nature, 406, 611-614, 2000.

Koop, T., Bookhold, J., Shiraiwa, M., and Pöschl, U.: Glass transition and phase state of organic compounds: dependency on molecular properties and implications for secondary organic aerosols in the atmosphere, Phys. Chem. Chem. Phys., 13, 19238-19255, 2011.

Lienhard, D. M., Zobrist, B., Zuend, A., Krieger, U. K., and Peter, T.: Experimental evidence for excess entropy discontinuities in glass-forming solutions, J. Chem. Phys., 136, 074514, doi:10.1063/1.3685902, 2012.

Martin, S. T.: Phase transitions of aqueous atmospheric particles, Chem. Rev., 100, 3403-3453, doi:10.1021/cr990034t, 2000.

Mikhailov, E., Vlasenko, S., Martin, S. T., Koop, T., and Pöschl, U.: Amorphous and crystalline aerosol particles interacting with water vapor: conceptual framework and experimental evidence for restructuring, phase transitions and kinetic limitations, Atmos. Chem. Phys., 9, 9491-9522, doi:10.5194/acp-9-9491-2009, 2009.

Murphy, D. M. and Koop, T.: Review of the vapour pressures of ice and supercooled water for atmospheric applications, Q. J. Roy. Meteorol. Soc., 131, 1539-1565, doi:10.1256/qj.04.94, 2005.
Murphy, D. M., Cziczo, D. J., Froyd, K. D., Hudson, P. K., Matthew, B. M., Middlebrook, A. M., Peltier, R. E., Sullivan, A., Thomson, D. S., and Weber, R. J.: Single-particle mass spectrometry of tropospheric aerosol particles, J. Geophys. Res.-Atmos., 111, D23s32, doi:10.1029/2006jd007340, 2006.

Murray, B. J.: Inhibition of ice crystallisation in highly viscous aqueous organic acid droplets, Atmos. Chem. Phys., 8, 54235433, doi:10.5194/acp-8-5423-2008, 2008.

Murray, B. J., Wilson, T. W., Dobbie, S., Cui, Z. Q., AlJumur, S., Mohler, O., Schnaiter, M., Wagner, R., Benz, S., Niemand, M., Saathoff, H., Ebert, V., Wagner, S., and Karcher, B.: Heterogeneous nucleation of ice particles on glassy aerosols under cirrus conditions, Nature Geoscience, 3, 233-237, doi:10.1038/ngeo817, 2010.

Murray, B. J., Haddrell, A. E., Peppe, S., Davies, J. F., Reid, J. P., O’Sullivan, D., Price, H. C., Kumar, R., Saunders, R. W., Plane, J. M. C., Umo, N. S., and Wilson, T. W.: Glass formation and unusual hygroscopic growth of iodic acid solution droplets with relevance for iodine mediated particle formation in the marine boundary layer, Atmos. Chem. Phys., 12, 8575-8587, doi:10.5194/acp-12-8575-2012, 2012.

Pruppacher, H. R. and Klett, J. D.: Microphysics of Clouds and Precipitation, Reidel, D., Norwell, Mass., 1997.

Roth, C. M., Goss, K. U., and Schwarzenbach, R. P.: Sorption of a diverse set of organic vapors to urban aerosols, Environ. Sci. Technol., 39, 6638-6643, doi:10.1021/es0503837, 2005.

Salameh, A. K., Mauer, A. K., and Taylor, L. S.: Implications of Deliquescence in Food and Pharmaceutical Products Ninth Topical Conference on Food Engineering (CoFE 2005) Cincinnati, OH, USA, 2 November 2005, 2005.

Saukko, E., Lambe, A. T., Massoli, P., Koop, T., Wright, J. P., Croasdale, D. R., Pedernera, D. A., Onasch, T. B., Laaksonen, A., Davidovits, P., Worsnop, D. R., and Virtanen, A.: Humiditydependent phase state of SOA particles from biogenic and anthropogenic precursors, Atmos. Chem. Phys., 12, 7517-7529, doi:10.5194/acp-12-7517-2012, 2012.

Schill, G. P. and Tolbert, M. A.: Depositional Ice Nucleation on Monocarboxylic Acids: Effect of the O : C Ratio, J. Phys. Chem. A, 116, 6817-6822, doi:10.1021/jp301772q, 2012a.

Schill, G. P. and Tolbert, M. A.: Heterogeneous ice nucleation on phase-separated organic-sulfate particles: effect of liquid vs. glassy coatings, Atmos. Chem. Phys., 13, 4681-4695, doi:10.5194/acp-13-4681-2013, 2013b.

Shiraiwa, M., Ammann, M., Koop, T., and Pöschl, U.: Gas uptake and chemical aging of semisolid organic aerosol particles, P. Natl. Acad. Sci. USA, 108, 11003-11008, doi:10.1073/pnas.1103045108, 2011.

Shiraiwa, M., Pöschl, U., and Knopf, D. A.: Multiphase Chemical Kinetics of $\mathrm{NO}_{3}$ Radicals Reacting with Organic Aerosol Components from Biomass Burning, Environ. Sci. Technol., 46, 6630-6636, doi:10.1021/es300677a, 2012.

Tong, H.-J., Reid, J. P., Bones, D. L., Luo, B. P., and Krieger, U. K.: Measurements of the timescales for the mass transfer of water in glassy aerosol at low relative humidity and ambient temperature, Atmos. Chem. Phys., 11, 4739-4754, doi:10.5194/acp-11-47392011, 2011.

Vaden, T. D., Imre, D., Beranek, J., Shrivastava, M., and Zelenyuk, A.: Evaporation kinetics and phase of laboratory and ambient secondary organic aerosol, P. Natl. Acad. Sci. USA, 108, 2190 
2195, doi:10.1073/pnas.1013391108, 2011.

Virtanen, A., Joutsensaari, J., Koop, T., Kannosto, J., Yli-Pirila, P., Leskinen, J., Makela, J. M., Holopainen, J. K., Pöschl, U., Kulmala, M., Worsnop, D. R., and Laaksonen, A.: An amorphous solid state of biogenic secondary organic aerosol particles, Nature, 467, 824-827, doi:10.1038/nature09455, 2010.

Wagner, R., Möhler, O., Saathoff, H., Schnaiter, M., Skrotzki, J., Leisner, T., Wilson, T. W., Malkin, T. L., and Murray, B. J: Ice cloud processing of ultra-viscous/glassy aerosol particles leads to enhanced ice nucleation ability, Atmos. Chem. Phys., 12, 85898610, doi:10.5194/acp-12-8589-2012, 2012.

Wang, B., Lambe, A. T., Massoli, P., Onasch, T. B., Davidovits, P., Worsnop, D. R., and Knopf, D. A.: The deposition ice nucleation and immersion freezing potential of amorphous secondary organic aerosol: pathways for ice and mixed-phase cloud formation, J. Geophys. Res., 117, D16209, doi:10.1029/2012jd018063, 2012a.

Wang, B., Laskin, A., Roedel, T., Gilles, M. K., Moffet, R. C., Tivanski, A., and Knopf, D. A.: Heterogeneous ice nucleation and water uptake by field-collected atmospheric particles below 273 K, J. Geophys. Res., 117, D00V19, doi:10.1029/2012JD017446, 2012b.

Wilson, T. W., Murray, B. J., Wagner, R., Möhler, O., Saathoff, H., Schnaiter, M., Skrotzki, J., Price, H. C., Malkin, T. L., Dobbie, S., and Al-Jumur, S. M. R. K.: Glassy aerosols with a range of compositions nucleate ice heterogeneously at cirrus temperatures, Atmos. Chem. Phys., 12, 8611-8632, doi:10.5194/acp-128611-2012, 2012.
Wise, M. E., Baustian, K. J., Koop, T., Freedman, M. A., Jensen, E. J., and Tolbert, M. A.: Depositional ice nucleation onto crystalline hydrated $\mathrm{NaCl}$ particles: a new mechanism for ice formation in the troposphere, Atmos. Chem. Phys., 12, 1121-1134, doi:10.5194/acp-12-1121-2012, 2012.

Zhang, Q., Jimenez, J. L., Canagaratna, M. R., Allan, J. D., Coe, H., Ulbrich, I., Alfarra, M. R., Takami, A., Middlebrook, A. M., Sun, Y. L., Dzepina, K., Dunlea, E., Docherty, K., DeCarlo, P. F., Salcedo, D., Onasch, T., Jayne, J. T., Miyoshi, T., Shimono, A., Hatakeyama, S., Takegawa, N., Kondo, Y., Schneider, J., Drewnick, F., Borrmann, S., Weimer, S., Demerjian, K., Williams, P., Bower, K., Bahreini, R., Cottrell, L., Griffin, R. J., Rautiainen, J., Sun, J. Y., Zhang, Y. M., and Worsnop, D. R.: Ubiquity and dominance of oxygenated species in organic aerosols in anthropogenically-influenced Northern Hemisphere midlatitudes, Geophys. Res. Lett., 34, L13801, doi:10.1029/2007g1029979, 2007.

Zobrist, B., Marcolli, C., Pedernera, D. A., and Koop, T.: Do atmospheric aerosols form glasses?, Atmos. Chem. Phys., 8, 52215244, doi:10.5194/acp-8-5221-2008, 2008.

Zobrist, B., Soonsin, V., Luo, B. P., Krieger, U. K., Marcolli, C., Peter, T., and Koop, T.: Ultra-slow water diffusion in aqueous sucrose glasses, Phys. Chem. Chem. Phys., 13, 3514-3526, doi:10.1039/c0cp01273d, 2011. 